\title{
PERSPECTIVE
}

\section{One Group's Historical Reflections on DNA Vaccine Development}

\author{
Ellen F. Fynan, Shan Lu, and Harriet L. Robinson ${ }^{3, *}$ \\ ${ }^{1}$ Department of Biology, Worcester State College, Worcester, Massachusetts; ${ }^{2}$ Department of Medicine, University of Massachusetts Medical School, Worcester, \\ Massachusetts; and ${ }^{3}$ GeoVax, Inc., Smyrna, Georgia.
}

DNA vaccines were pioneered by several groups in the early 1990s. This article presents the reflections of one of these groups on their work with retroviral vectors in chickens that contributed to the discovery and early development of DNA vaccines. Although the findings were initially met with skepticism, the work presented here combined with that of others founded a new method of vaccination: the direct inoculation of purified DNA encoding the target antigen.

Keywords: DNA vaccines, antibody, cytotoxic T cells, heterologous prime-boost

IN 1992, OUR LABORATORY was one of the pioneers on the use of in vivo DNA-expressed proteins to elicit protective immune responses. As with many novel concepts, this "radical" method of vaccination met with skepticism and doubt. Jenner self-published his use of variolation to protect against smallpox because the Royal Society considered that they might damage the Society's reputation by publishing his findings in the Proceedings of the Royal Society. ${ }^{1}$ So too, the idea of using DNA as a vaccine was first considered questionable. However, convincing experimental evidence from our laboratory and others over the past 25 years has demonstrated the powerful potential of this method for immunization and contributed to the use of in vivo expression of DNA-encoded proteins for gene therapy, cancer immunotherapy, and monoclonal antibody production. ${ }^{2-4}$

The development of live vaccinia virus as an expression vector and its use as a vaccine in 1982 generated interest in the use of viral vectors for vaccination. ${ }^{5,6}$ Recognizing the potential of this method and possible extension to avian diseases, our group inserted the gene for avian influenza hemagglutinin, the major target for protective antibody, into a replication-competent avian retrovirus vector. ${ }^{7}$ Transfection of the recombinant retroviral vector into chick embryo fibroblasts resulted in production of the vector and expression of the influenza hemagglutinin insert for $>2$ weeks. In experiments conducted in collaboration with Rob Webster of St. Jude's Children's Research Hospital (which had the appropriate BSL3 laboratory for testing avian influenza virus infections in chickens), the retroviral vector-based vaccine completely protected chickens against a lethal influenza virus challenge. ${ }^{7}$ In contrast, birds within the control group succumbed to influenza. Given this, we next tested an infectious, replication-defective pseudotype of the retroviral vector for the ability to provide protection. This replication-defective pseudotype, despite inoculating $<1 \times 10^{6}$ infectious units, also achieved $100 \%$ protection, demonstrating that even low titers of a replication-defective vector could achieve protective immunity.

Retroviruses have DNA and RNA forms of their genetic information: RNA in infectious virus and DNA in infected cells. Given the ability of relatively few infectious units of the infectious, replication defective pseudotype to achieve protection and a growing body of evidence for successful in vivo transfection, ${ }^{8,9}$ we tested the ability of the DNA forms of both the replication-competent and replication-defective vectors to achieve protection. We made as much DNA as we could and asked Rob to vaccinate chickens with $300 \mu \mathrm{g}$ of vaccine DNA

*Correspondence: Dr. Harriet L. Robinson, GeoVax, Inc., 1900 Lake Park Drive, Suite 380, Smyrna, GA 30080. E-mail: hrobinson@geovax.com

(C) Ellen F. Fynan et al. 2018; Published by Mary Ann Liebert, Inc. This Open Access article is distributed under the terms of the Creative Commons License (http://creativecommons.org/licenses/by/4.0), which permits unrestricted use, distribution, and reproduction in any medium, provided the original work is properly cited. 
or empty vector DNA (the control). Each chicken received $300 \mu \mathrm{g}$ of DNA at weeks 0 and 4 delivered by three routes (subcutaneous, intraperitoneal, and intravenous). A lethal influenza virus challenge was administered at week 5 . We learned that our first DNA experiment had worked when Rob left the message "Send more vaccine." We had achieved $100 \%$ protection in both groups of chickens, receiving either the replication-competent or the replication-defective vectors. We immediately set out to repeat the trial, telling nobody of the result until a patent had been filed. Once we had filed, we began to present the results, but these were met with disdain and skepticism. The first question at the summer 1992 American Society of Virology meeting was "You don't think this will ever be useful, do you?" Our grants were triaged and our manuscripts returned (despite Nature sending the report to multiple reviewers). Fortunately, our department chair, Guido Majno, a pathologist with broad interests in the history of science and medicine and author of the bestselling book, The Healing Hand, recognized the potential of what we were doing and provided departmental funds to keep us going. We knew we were onto something, and we kept going.

The new technology first achieved public acceptance at the fall 1992 Cold Spring Harbor Vaccine meeting, "Modern Approaches to New Vaccines," which was attended by a number of the early players in DNA vaccines. We presented our protective studies in chickens and mice. Margaret Liu, Jeff Ulmer, and John Donnelly of Merck showed that protective cytotoxic T cells could be elicited, David Weiner from the University of Pennsylvania described the generation of $\mathrm{Ab}$ responses for human immunodeficiency virus type 1 (HIV-1), and researchers from Vical presented their results on introducing DNA into muscle. The attendees clustered around the DNA posters. The field of DNA vaccines had been born! That fall, the Department of Agriculture awarded our first funding for DNA vaccines, and Shan Lu, a new postdoctoral fellow in the lab, received a Howard Hughes fellowship for studying DNA-based immunizations. It would, however, take another year and increasing sophistication in immunology on our part to "merit" National Institutes of Health funding.

Taken together, it was becoming clear that transfection could occur in vivo and that low numbers of cells expressing a plasmid were sufficient to stimulate an immune response. However, given the concern that an endogenous virus might render our replication-defective retroviral vectors infectious, we undertook in vivo antigen expression with a non-retroviral DNA vector, comprised of a mammalian expression plasmid with the gene for the influenza hemagglutinin antigen under the control of a strong eukaryotic promoter. These studies readily replicated the success achieved with the retroviral vectors.

With protection against disease shown in DNAvaccinated chickens, we moved our studies into much more tractable mouse models. Influenza hemagglutinin expressing plasmid DNA successfully protected $\mathrm{BALB} / \mathrm{c}$ mice following intramuscular and intravenous inoculations using a hypodermic needle and syringe; intranasal inoculations, using nose drops; and epidermal inoculations using a gene gun. A prototype gene gun (Accell ${ }^{\circledR}$ ) was acquired from Agracetus (Middleton, WI) where it had been developed primarily to introduce DNA into plant cells and, later, live animals. ${ }^{10-12}$ In our experiments, we used the gene gun to blast gold particles coated with the plasmid DNA into the shaved abdominal skin of mice. In earlier biolistic studies, Stephen Johnston had used a gene gun to deliver human growth hormone to the outer ears of mice and realized that he had not affected mouse growth but had elicited $\mathrm{Ab}$ to human growth hormone. ${ }^{13}$ The use of the Agracetus gun (the size of a refrigerator) generated a great deal of excitement (and noise) within the department, but did not allay suspicions about our laboratory's endeavors.

Our initial experiments in mice were highly successful: $95 \%$ of the mice inoculated intramuscularly survived the lethal influenza virus challenge. Even more striking were the results of the gene gun inoculations. Mice were protected against an influenza challenge virus with 250-2,500 times less plasmid DNA than with the other routes of administration. ${ }^{14}$ These results-along with pioneering work by Jon Wolff of the University of Wisconsin and Phillip Felgner of Vical on intramuscular delivery of DNA; ${ }^{15}$ Margaret Liu, Jeff Ulmer, and John Donnelly at Merck, which had licensed the delivery of "naked DNA" to muscle from Vical; ${ }^{16}$ Stephen Johnston of the Southwestern Medical Center on ballistic delivery of DNA to elicit $\mathrm{Ab} ;{ }^{13,16}$ David Weiner of the University of Pennsylvania; ${ }^{17}$ Heather Davis and Bob Whalen of the Pasteur Institute ${ }^{18,19}$ Hildegund Ertl of the Wistar Institute ${ }^{20}$ and Britta Wahren of the Karolinska Institute $^{19}$-gained acceptance for this new vaccination method and encouraged others to try this novel avenue of vaccine research. ${ }^{21}$

Given the ease of DNA vaccine construction and manufacture, early DNA vaccines had reached the clinic within 5 years of the first demonstration of 
Table 1. Timeline for DNA vaccines

\begin{tabular}{ll}
\hline 1992 & Demonstration of the ability to elicit antibody \\
1993 & First protective studies in animals \\
1994 & Naming of technology, WHO \\
1995 & First prophylactic Phase I human trial \\
1996 & $\begin{array}{l}\text { FDA points to consider for DNA-based vaccines } \\
\text { d }\end{array}$ \\
1998 & $\begin{array}{l}\text { HIV, malaria, influenza, herpes, and hepatitis B virus vaccines } \\
\text { in clinical trials }\end{array}$
\end{tabular}

\footnotetext{
aDemonstrated in a "gene therapy" experiment in which human growth hormone was being delivered to mice to enhance growth.

${ }^{\mathrm{b}}$ Names under consideration included genetic immunization, polynucleotide immunization, gene vaccines, and DNA vaccines.

${ }^{\mathrm{c}}$ This first prophylactic trial, a Merck plasmid expressing influenza hemagglutinin, was never published due to it not having worked and Mary Lou Clements-Mann of Johns Hopkins, its P.I., having died in the crash of Swiss Air, flight 111.

${ }^{\mathrm{d}}$ Points to consider present guidelines for the manufacture of vaccines. WHO, World Health Organization; FDA, Food and Drug Administration; HIV, human immunodeficiency virus.
}

in vivo immunogenicity (Table 1). Despite the extraordinarily rapid reduction of this new technique to clinical use, we are now 25 years out and do not have a single licensed DNA vaccine for humans. Part of this is due to DNA vaccines having been used for the development of vaccines for chronic infections, such as HIV, tuberculosis, and malaria, which are difficult targets for vaccination. A second important factor is the low level of immune responses that are elicited by DNA vaccines when used alone or without assisted delivery such as by electroporation.

The elicitation of low-titer antibody responses was evident in our earliest experiments in chicken where large amounts of DNA ( $300 \mu \mathrm{g}$ of DNA) raised essentially undetectable $\mathrm{Ab}$ responses. The "undetectable" Ab responses did undergo strong anamnestic expansions post challenge, sufficiently strong to protect against infections that could kill within a week of challenge. These strong anamnestic responses differed from anamnestic responses primed by a natural infection by being focused on the antigen primed by the vaccine, rather than the totality of the immunogenic proteins of an infection. ${ }^{22}$

This characteristic of DNA vaccines, the elicitation of low but specific responses, is the foundation for the currently popular use of DNA to prime responses that are then boosted by a live vector, peptide, or protein. ${ }^{23}$ In these heterologous primeboost regimens, the DNA focuses the immune response on its vaccine insert, promotes antigenspecific B-cell development at the germinal center of lymph nodes, and activates the innate immune system to promote acquired immunity. ${ }^{24,25}$ Live vectors such as modified vaccinia Ankara are then used to boost the memory response for the vaccine antigens, which occurs largely to the exclusion of the antigens present in the boosting vector. Protein boosts are most effective for the epitopes that are common to the DNA-expressed antigen and the boost. In this case, the DNA-expressed antigen can serve to focus the boost on epitopes that represent the native antigen. These are readily preserved on DNA-expressed proteins but trickier to preserve on protein immunogens that need to undergo production, purification, and storage.

Heterologous prime boosts can be highly effective for eliciting high levels of $\mathrm{CD}^{+} \mathrm{T}^{-}$cells ${ }^{26,27}$ and antibody. ${ }^{28,29}$ They are, however, cumbersome for the development of real-world vaccines because they require two different products that need to be used in the correct order. Thus, they can be expensive to manufacture and deliver. Recently, however, successful vaccination, including the generation of neutralizing $\mathrm{Ab}$, has been achieved in nonhuman primates with a DNA vaccine for Zika virus using only two intramuscular bioject deliveries of the vaccine preparation. ${ }^{30}$ Following challenge, 95\% (17/18) of the animals had no detectable viremia. Currently, this Zika virus DNA vaccine candidate is in Phase I clinical trials (ClinicalTrials.gov NCT02840487). This success reflects the high immunogenicity of the Zika glycoprotein, and sets a precedent for DNA immunizations with other highly immunogenic proteins holding good promise for success. Following electroporation, Ebola, Marburg, and Middle East respiratory syndrome (MERS) vaccines have shown promise in nonhuman primates, ${ }^{31,32}$ and the MERS vaccine has been advanced to clinical trials (ClinicalTrials.gov NCT02670187).

As DNA vaccines have undergone development, many advances have been made in DNA expression and delivery. Jet injectors, ${ }^{33}$ improved liposomes, ${ }^{34,35}$ and electroporation ${ }^{36}$ have enhanced responses through increased efficiency of DNA delivery. Work on expression cassettes has identified promoters, enhancers, and introns that optimize responses. ${ }^{37}$ Pathogen genes have been codon optimized for human usage to enhance expression. ${ }^{38}$ The elicitation of immune responses has been modulated by removing (to tolerize) ${ }^{39}$ or increasing

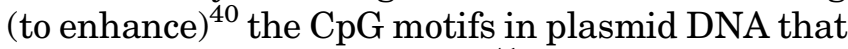
stimulate innate responses. ${ }^{41}$ Extensive studies have employed genetic (DNA-encoded) adjuvants to enhance and shape immune responses. ${ }^{20,42}$ Gene guns, however, have not advanced from being a tool suited to the laboratory to general use so far, but there is renewed effort by Deborah Fuller from the University of Washington on this approach.

As for the authors, we are still using DNA for vaccination. Two of us are using heterologous prime-boost regimens for the development of a HIV 
vaccine. One of us (H.L.R.) is using the DNA as a prime for modified vaccinia Ankara boosts. ${ }^{43-45}$ In this case, the DNA facilitates the display of the native form of the HIV Env on virus like particles. Another (S.L.) is using DNA as a prime for gp120 protein subunit boosts as part of a polyvalent HIV vaccine strategy. The last (E.F.F.) is teaching the next generation of experimental biologists.

\section{ACKNOWLEDGMENTS}

The authors would like to acknowledge Joe Santoro for his technical support of the early DNA vaccine experiments in the Robinson laboratory.
We are eternally indebted to Dr. Guido Majno for his provision of Departmental support for our early work on DNA vaccines and to the Howard Hughes Medical Institute for having supported postdoctoral work on DNA vaccines for S.L.

\section{AUTHOR DISCLOSURE}

H.L.R. currently works for GeoVax, Inc., which is advancing a DNA prime-MVA boost vaccine. She owns stock in GeoVax as well as being on patents. S.L. is on DNA vaccine-related patents. E.F.F. is on DNA vaccine-related patents.

\section{REFERENCES}

1. Jenner E. An Inquiry into the Causes and Effects of the Variolae Vaccine. London: Sampson Low, 1798

2. Hardee CL, Arevalo-Soliz LM, Hornstein BD, et al. Advances in non-viral DNA vectors for gene therapy. Genes (Basel) 2017:8:65.

3. Tiptiri-Kourpeti A, Spyridopoulou K, Pappa A, et al. DNA vaccines to attack cancer: strategies for improving immunogenicity and efficacy. Pharmacol Ther 2016;165:32-49.

4. Liu S, Wang S, Lu S. DNA immunization as a technology platform for monoclonal antibody induction. Emerg Microbes Infect 2016;5:e33.

5. Mackett M, Smith GL, Moss B. Vaccinia virus: a selectable eukaryotic cloning and expression vector. Proc Natl Acad Sci U S A 1982;79:7415-7419.

6. Panicali D, Paoletti E. Construction of poxviruses as cloning vectors: insertion of the thymidine kinase gene from herpes simplex virus into the DNA of infectious vaccinia virus. Proc Natl Acad Sci U S A 1982;79:4927-4931.

7. Hunt LA, Brown DW, Robinson HL, et al. Retrovirusexpressed hemagglutinin protects against lethal influenza virus infections. J Virol 1988;62:30143019 .

8. Israel MA, Chan HW, Hourihan SL, et al. Biological activity of polyoma viral DNA in mice and hamsters. J Virol 1979;29:990-996.

9. Halpern MS, Ewert DL, England JM. Wing web or intravenous inoculation of chickens with v-src DNA induces visceral sarcomas. Virology 1990; 175:328-331

10. Christou P, McCabe DE, Swain WF. Stable transformation of soybean callus by DNA-coated gold particles. Plant Physiol 1988;87:671-674.

11. Williams RS, Johnston SA, Riedy $M$, et al. Introduction of foreign genes into tissues of living mice by DNA-coated microprojectiles. Proc Natl Acad Sci U S A 1991;88:2726-2730.

12. Sanford JC, Smith FD, Russell JA. Optimizing the biolistic process for different biological applications. Methods Enzymol 1993;217:483-509.
13. Tang DC, De Vit M, Johnston SA. Genetic immunization is a simple method for eliciting an immune response. Nature 1992;356:152-154.

14. Fynan EF, Webster RG, Fuller DH, et al. DNA vaccines: protective immunizations by parenteral, mucosal, and gene-gun inoculations. Proc Natl Acad Sci U S A 1993;90:11478-11482.

15. Wolff JA, Malone RW, Williams P, et al. Direct gene transfer into mouse muscle in vivo. Science 1990;247:1465-1468.

16. Ulmer JB, Donnelly JJ, Parker SE, et al. Heterologous protection against influenza by injection of DNA encoding a viral protein. Science 1993;259: 1745-1749.

17. Wang B, Ugen KE, Srikantan V, et al. Gene inoculation generates immune responses against human immunodeficiency virus type 1. Proceedings of the National Academy of Sciences U S A 1993:90:4156-4160.

18. Davis HL, Michel ML, Whalen RG. DNA-based immunization induces continuous secretion of hepatitis B surface antigen and high levels of circulating antibody. Hum Mol Genet 1993;2: 1847-1851.

19. Calarota S, Bratt G, Nordlund S, et al. Cellular cytotoxic response induced by DNA vaccination in HIV-1-infected patients. Lancet 1998;351:1320 1325

20. Xiang Z, Ertl HC. Manipulation of the immune response to a plasmid-encoded viral antigen by coinoculation with plasmids expressing cytokines. Immunity 1995:2:129-135.

21. Robinson HL, Ginsberg HS, Davis HL, et al. The Scientific Future of DNA for Immunization. Washington, DC: American Academy of Microbiology, 1997

22. Robinson HL, Hunt LA, Webster RG. Protection against a lethal influenza virus challenge by immunization with a haemagglutinin-expressing plasmid DNA. Vaccine 1993;11:957-960.

23. Lu S. Heterologous prime-boost vaccination. Curr Opin Immunol 2009;21:346-351.
24. Suschak JJ, Wang S, Fitzgerald KA, et al. A cGASindependent STING/IRF7 pathway mediates the immunogenicity of DNA vaccines. J Immunol 2016;196:310-316.

25. Hollister K, Chen $Y$, Wang $S$, et al. The role of follicular helper T cells and the germinal center in HIV-1 gp120 DNA prime and gp120 protein boost vaccination. Hum Vaccin Immunother 2014;10:1985-1992.

26. Schneider J, Gilbert SC, Hannan CM, et al. Induction of CD8+ T cells using heterologous primeboost immunisation strategies. Immunol Rev 1999; 170:29-38.

27. Amara RR, Villinger F, Altman ND, et al. Control of a mucosal challenge and prevention of AIDS by a multiprotein DNA/MVA vaccine. Science 2001; 292:69-74.

28. Richmond JF, Mustafa F, Lu S, et al. Screening of HIV-1 Env glycoproteins for the ability to raise neutralizing antibody using DNA immunization and recombinant vaccinia virus boosting. Virology 1997;230:265-274.

29. Richmond JF, Lu S, Santoro JC, et al. Studies of the neutralizing activity and avidity of anti-human immunodeficiency virus type 1 Env antibody elicited by DNA priming and protein boosting. J Virol 1998;72:9092-9100.

30. Dowd KA, Ko S-Y, Morabito KM, et al. Rapid development of a DNA vaccine for Zika virus. Science 2016:354:237-240.

31. Shedlock DJ, Aviles J, Talbott KT, et al. Induction of broad cytotoxic $T$ cells by protective DNA vaccination against Marburg and Ebola. Mol Ther 2013;21:1432-1444.

32. Muthumani K, et al. A synthetic consensus antispike protein DNA vaccine induces protective immunity against Middle East respiratory syndrome coronavirus in nonhuman primates. Sci Transl Med 2015;7:301ra132.

33. Graham BS, Enama ME, Nason MC, et al. DNA vaccine delivered by a needle-free injection device improves potency of priming for antibody and CD8+ T-cell responses after rAd5 boost in a randomized clinical trial. PLoS One 2013;8:e59340. 
34. Felgner PL. Improvements in cationic liposomes for in vivo gene transfer. Hum Gene Ther 1996; 1791-1793.

35. Sullivan SM, Doukas J, Hartikka J, et al. Vaxfectin: a versatile adjuvant for plasmid DNA- and protein-based vaccines. Expert Opin Drug Deliv 2010;7:1433-1446.

36. Widera G, Austin M, Rabussay D, et al. Increased DNA vaccine delivery and immunogenicity by electroporation in vivo. J Immunol 2000;164:4635-4640.

37. Chapman BS, Thayer RM, Vincent KA, et al. Effect of intron A from human cytomegalovirus (Towne) immediate-early gene on heterologous expression in mammalian cells. Nucl Acids Res 1991;19: 3979-3986.

38. Andre S, Seed B, Eberle J, et al. Increased immune response elicited by DNA vaccination with a synthetic gp120 sequence with optimized codon usage. J Virol 1998;72:1497-1503.
39. Ho PP, Fontoura P, Platten M, et al. A suppressive oligodeoxynucleotide enhances the efficacy of myelin cocktail/LL-4-tolerizing DNA vaccination and treats autoimmune disease. J Immunol 2005; 175:6226-6234.

40. Klinman DM, Yamshchikov G, Ishigatsubo Y Contribution of $\mathrm{CpG}$ motifs to the immunogenicity of DNA vaccines. J Immunol 1997;158:36353639

41. Ashkar AA, Rosenthal KL. Toll-like receptor 9, CpG DNA and innate immunity. Curr Mol Med 2002;2: 545-556.

42. Kim JJ, Bagarazzi ML, Trivedi N, et al. Engineering of in vivo immune responses to DNA immunization via codelivery of costimulatory molecule genes. Nat Biotechnol 1997:15:641-646.

43. Goepfert PA, Elizaga ML, Sato A, et al. Phase 1 safety and immunogenicity testing of DNA and recombinant modified vaccinia Ankara vaccines expressing HIV-1 virus-like particles. J Infect Dis 2011:203:610-619.

44. Goepfert PA, et al. Specificity and 6-month durability of immune responses induced by DNA and recombinant modified vaccinia Ankara vaccines expressing HIV-1 virus-like particles. J Infect Dis 2014;210:99-110.

45. Buchbinder SP, Grunenberg NA, Sanchez BJ, et al Immunogenicity of a novel Clade B HIV-1 vaccine combination: results of Phase 1 randomized placebo controlled trial of an HIV-1 GM-CSFexpressing DNA prime with a modified vaccinia Ankara vaccine boost in healthy HIV-1 uninfected adults. PLoS One 2017;12:e0179597.

Received for publication March 30, 2018; accepted after revision June 30, 2018

Published online: July 2, 2018 